\title{
ACUTE TOXICITY STUDIES OF GLUCURONOXYLAN POLYSACCHARIDES FROM SEEDS OF QUINCE (CYDONIA OBLONGA)
}

\author{
MUHAMMAD UMER ASHRAF, ${ }^{*}$ MUHAMMAD AJAZ HUSSAIN, ${ }^{* *}$ \\ MUHAMMAD TAHIR HASEEB, ${ }^{*}$ ALIA ERUM ${ }^{*}$ and MUHAMMAD NAVEED MUSHTAQ* \\ ${ }^{*}$ College of Pharmacy, University of Sargodha, Sargodha 40100, Pakistan \\ ** Department of Chemistry, University of Sargodha, Sargodha 40100, Pakistan \\ ๔ Corresponding author: M. A. Hussain,majaz172@yahoo.com
}

Received January 20, 2019

\begin{abstract}
Acute toxicity studies of glucuronoxylan polysaccharide isolated from Cydonia oblonga M. (quince) seeds were performed on white albino mice and rabbits. Quince seed polysaccharides (QSP) were administered orally to groups II, III and IV in different doses, i.e., 1, 2 and $5 \mathrm{~g} / \mathrm{kg}$ body weight, respectively. Group I was assigned as control and left untreated. Body weight, food and water intake of mice were monitored before and after administration of QSP on day 1, 2, 3, 7 and 14. Furthermore, the mice were also monitored for any symptoms of tremors, allergy, diarrhea, vomiting and abnormal reflexes for $8 \mathrm{~h}$ after oral administration of QSP. On the $15^{\text {th }}$ day, blood samples of the control and treated group animals were collected for determining the haematological and serum biochemical parameters. The relative organ body weight of all vital organs was calculated and their histopathology was studied. The study revealed that there was no significant difference in body weight, food and water consumption. The behavioral pattern of the control and treated animals was alike. The haematological and biochemical parameters of the treated animals were comparable with those of the control group animals. The relative organ body weight of the animals from all the groups has not shown any significant difference. The histopathology of vital organs of both control and treated animals showed no lesions, establishing oral safety of QSP. Studies of dermal, ocular and cardiac toxicity of QSP were performed on rabbits and established the quince seed polysaccharide to be a safe excipient for drug delivery systems.
\end{abstract}

Keywords: acute toxicity, haematology, histopathology, quince polysaccharides, glucuronoxylan

\section{INTRODUCTION}

Oral drug delivery is widely accepted due to convenient drug administration and economy offered by this route. However, low bioavailability is one of the major challenges associated with this route. ${ }^{1,2}$ This flaw could be circumvented by designing gastro-retentive drug delivery systems. ${ }^{3}$ In this context, different drug delivery systems based on muco-adhesive polymers, ${ }^{4}$ floating ion exchange resins, ${ }^{5}$ superporous hydrogels ${ }^{6-8}$ etc. have been investigated. Among these systems, hydrogels have been proved as the most successful and efficient drug carriers, modulating drug release in response to external stimuli, such as $\mathrm{pH}$, temperature, ionic strength. ${ }^{9-12}$

Hydrogels are superporous water swellable materials, comprising a three-dimensional network of hydrophilic polymers, held together by means of covalent or ionic crosslinks between different chains or by means of hydrogen bonding. ${ }^{13}$ Naturally occurring hydrogels are now the focus of many researchers in various pharmaceutical and biomedical applications due to their biocompatibility, biodegradability, nonimmunogenicity and easy availability. These hydrogels are mainly polysaccharides, such as sodium alginate, ${ }^{14-16}$ hyaluronic acid, ${ }^{17}$ guar gum, ${ }^{18}$ chitosan, ${ }^{19-21}$ carrageenan, ${ }^{22}$ and arabinoxylan, ${ }^{23-25}$ and are widely used in various drug delivery systems. ${ }^{26,27}$ Due to the immense importance of naturally occurring polysaccharides, it is worth developing new materials for pharmaceutical and biomedical applications. The toxicological evaluation of new materials is prerequisite for their potential application in various drug delivery systems. Recently, naturally occurring polysaccharides have been evaluated through acute toxicity studies for potential pharmaceutical applications. ${ }^{28,29}$ 
Cydonia oblonga M. (Rosacea family; commonly known as quince) is native to Turkey and Iran, but also grows in the sub-Himalayan regions of South Asia. Traditionally, it is renowned for its medicinal attributes. It is used for treatment of gastrointestinal, urinary and cardiac disorders. ${ }^{30,31}$ Quince leaf decoctions have been used as diuretic and in treating kidney stones in some parts of Turkey. ${ }^{32}$ The cell protecting potential, ${ }^{30,31,33}$ anti-proliferative, ${ }^{34}$ antimicrobial $^{31}$ and anti-hyperlipidemic activities of quince decoctions, ${ }^{35,36}$ as well as their potential use against auto-immune reactions, have also been reported. $^{37}$

Quince seeds extruded hydrogel-able polysaccharides (glucuronoxylan, QSP) were obtained through the hot water extraction method. Glucuronic acid is the main component of glucuronoxylan. A NMR study has shown that 4$O$-methyl- $\alpha$-D-glucopyranosyluronic and $\alpha$-Dglucopyranosyluronic acids are attached at position 2 of $(1 \rightarrow 4)-\beta$-D-xylan present in the long chain of glucuronoxylan. ${ }^{38}$

Looking at the potential utility of such naturally occurring hydrogel-able polysaccharides in the biomedical field, folk medicines and food and confectionary, we focused on establishing the oral safety of one of the most valuable polysaccharides - glucuronoxylan (QSP). For this purpose, the acute toxicity study of QSP was conducted on white albino mice and rabbits in accordance with the guidelines of the Organization for Economic Co-operation and Development (OECD, 2001) ${ }^{39}$ and National Institute of Health for the care and use of laboratory animals.

\section{EXPERIMENTAL Material}

Quince seeds were procured from a local market of Sargodha, Pakistan. Taxonomic identification of the seeds was carried out by a botanist from the Department of Biological Sciences, University of Sargodha, Sargodha, Pakistan, and after sieving, they were stored in a tightly closed container.

\section{Isolation of QSP from seeds}

QSP was isolated from quince seeds as described elsewhere. ${ }^{40}$ Briefly, after washing, the quince seeds were soaked in deionized water for 6-7 h. In order to get maximum yield of QSP, the soaked seeds were heated at $50{ }^{\circ} \mathrm{C}$ for $30 \mathrm{~min}$. The extruded mucilage was separated from the seeds by filtration through cotton cloth and washed with $n$-hexane in order to remove fatty material. The mucilage was processed through centrifugation to separate QSP and dried in hot air oven at $60{ }^{\circ} \mathrm{C}$ for $48 \mathrm{~h}$. Dried QSP was ground to fine powder and passed through a sieve of mesh no. 60 before being stored in a container for further study.

\section{Selection of animals and observation of physical parameters}

This study was carried out on twenty-four healthy albino mice weighing 25-30 g (aging 7-8 weeks) and albino rabbits (1150-1250 g) of either sex obtained from the University of Sargodha. The animals were kept in neat and clean cages at controlled temperature $\left(25{ }^{\circ} \mathrm{C}\right)$ and humidity $(50-60 \%)$ under light (for $12 \mathrm{~h}$ ) and dark (for $12 \mathrm{~h}$ ) cycles. Selected mice were shifted to the laboratory one week prior to the experiment for acclimatization and were randomly distributed into four groups, each containing six animals. Group I was kept untreated and labeled as control, whereas groups II-IV were treated with different doses of QSP. All the animals were fed with standard rodent diet and tap water. Free access to food and water was provided to all the animals during the study. However, the animals were kept in fasting condition for $12 \mathrm{~h}$ before conducting the toxicity studies. QSP was given in pellet form prepared by mixing QSP with sucrose and moistened with water. These pellets were administered orally to the animals of groups II, III and IV, and contained QSP equivalent to 1,2 and $5 \mathrm{~g} / \mathrm{kg}$ body weight, respectively. Group I was used as control and given water only. The animals were provided standard food $1 \mathrm{~h}$ after administration of QSP. All the animals were closely monitored for reflexes, salivation, diarrhea, tremors, allergic reactions, sleep, coma, change in skin color, effect on fur or mucous membrane, behavior pattern and mortality for $8 \mathrm{~h}$ after administration of QSP pellets and on daily basis for 14 days. Any abnormal change was recorded and compared with the control animals. The evaluation of acute toxicity of QSP was carried out in accordance to the guidelines of OECD. ${ }^{39}$

The body weight of the mice of both control and treated groups was recorded individually before and on day 1, 2, 3, 7 and 14 after the administration of QSP. The estimation of food and water consumed by the treated group was carried out before and after the treatment in a similar manner and compared with the control group.

The protocol followed during the current study was approved by the Institutional Research Ethics Committee (IREC) of the University of Lahore, Lahore, Pakistan, and was performed under the constant guidance of pharmacologists at the Department of Pharmacy, University of Sargodha, Sargodha, Pakistan.

\section{Ocular irritation test}

In order to test the ocular safety of QSP, six healthy albino rabbits were used as test animals. Two drops from an aqueous suspension of QSP $(5 \mathrm{mg} / 10 \mathrm{~mL})$ 
were instilled onto the lower averted lid of the right eye of each test animal with a dropper, whereas the left eye was kept untreated and used as control. The eyes of each animal were examined for pupil or corneal irritation, redness, lacrimation, swelling or any other abnormality after 1, 12, 24, 36, 48 and $72 \mathrm{~h}$ of administration of the QSP suspension and compared with the control. Ocular irritation and lesion were classified according to the score system of Kay and Calandra ${ }^{41}$ and Draize's scale, ${ }^{42}$ respectively.

\section{Evaluation of dermal toxicity}

To evaluate dermal toxicity of QSP, six albino rabbits were selected and were shaved on the back. A paste of QSP $(2 \% \mathrm{w} / \mathrm{v})$ was prepared in deionized water and spread onto a gauze $(4 \times 4 \mathrm{~cm})$ supported with adhesive Micropore ${ }^{\mathrm{TM}}$ tape in order to keep it intact on the skin of the rabbit. The skin color and the presence of rashes or allergic symptoms in the treated rabbits were compared with the condition of the control after 6,12, 24 and $48 \mathrm{~h}$ of the application of QSP.

\section{Relative organ weight}

On completion of the toxicity studies $\left(15^{\text {th }}\right.$ day), all the albino mice were sacrificed. Autopsy of all vital organs, i.e., heart, kidney, lungs, spleen, liver and gastrointestinal tract, was carried out and all the organs were examined macroscopically for lesions. The weight of each organ of both control and treated animals was recorded (absolute weight). Relative organ body weight (ROW) was determined using Equation 1: ${ }^{43}$

$R O W=\frac{\text { Absolute weight of organ }}{\text { Total body weight of mice }}$

\section{Histopathology of vital organs}

To examine the effects of QSP on cellular architecture, the histopathology of vital organs was carried out. For this purpose, all the animals were sacrificed and their vital organs (liver, heart, kidney, intestinal mucosa and spleen) were removed and preserved in $10 \%(\mathrm{v} / \mathrm{v})$ formalin solution. For the histological examination, a piece of organ $(5-7 \mu \mathrm{m})$ was cut with a rotary microtome, fixed on a glass slide and stained with haematoxylin and eosin for microscopic examination. The slides were examined under a binocular microscope (XSZ $107 \mathrm{BN}$ ).

\section{Haematology and biochemical analysis of blood}

On the $15^{\text {th }}$ day, blood samples of all the mice were collected before necropsy. The mice were anesthetized with chloroform and blood was drawn by cardiac puncture from the posterior vena cava with the help of a $22 \mathrm{G}$ syringe needle. Blood haemoglobin $(\mathrm{Hb})$, red blood cells (RBCs), white blood cells (WBCs) and platelet counts were carried out. Biochemical tests, such as liver profile, renal function and lipid profile, were also determined with the help of the biolyser.

\section{Safety pharmacology study}

The evaluation of all excipients for pharmacological activity is mandatory as per the guidelines of the International Conference of Harmonization (ICH). ${ }^{44}$ Safety pharmacology studies of excipients can be conducted as part of the toxicology evaluation and can also be performed independently. The toxicological effect of QSP on isolated heart of albino rabbits was evaluated using the procedure described earlier. ${ }^{45}$

Langendorff's technique was followed with some modifications. The rabbits were injected with $1000 \mathrm{IU}$ of heparin intravenously through a marginal ear vein 30 min before making them unconscious. The chest was opened with a scissor and the heart was dissected out with about $1 \mathrm{~cm}$ of aorta attached and quickly washed with oxygenated Ringers solution $(\mathrm{NaCl}, 45.0$ g; $\mathrm{NaHCO}_{3}, 1.0 \mathrm{~g}$; D-glucose, $5.0 \mathrm{~g} ; \mathrm{KCl}, 2.1 \mathrm{~g}$ and $\mathrm{CaCl}_{2} .2 \mathrm{H}_{2} \mathrm{O}, 1.6 \mathrm{~g}$ in $5 \mathrm{~L}$ distilled water). The isolated heart was gently squeezed several times to remove as much residual blood as possible. The heart was then transferred to the perfusion apparatus, Radnoti Isolated Heart System (AD Instrument, Australia) and tied to a glass cannula through the aorta. The perfusion was continuously bubbled with a mixture of $95 \% \mathrm{O}_{2}$ and $5 \% \mathrm{CO}_{2}$. The temperature was continuously monitored by a thermo-probe inserted into the perfusion fluid tank and maintained at $37.5 \pm 0.5^{\circ} \mathrm{C}$.

The heart was stabilized for $30 \mathrm{~min}$ before any drug administration. The mechanical responses, i.e., the force of contraction (FC) of the spontaneously contracting isolated heart was recorded by attaching one end of a thread to the apex of the heart using a Palmer clip and other end of the thread to a force displacement transducer (MLT 844; AD Instruments, Australia). The heart rate (HR) was calculated indirectly using Lab ChartPro 5 software (AD Instruments, Australia). The signals from the force transducer were filtered and amplified and sent to an analog-to-digital converter (Power Lab Data Acquisition and Analysis System of AD Instruments, Australia) attached to a computer. The signals recorded were saved for later analysis. FC and HRs were recorded and analyzed with the help of Lab ChartPro 5 software.

After stabilization of the heart, different doses of QSP (1 ng, $10 \mathrm{ng}, 0.1 \mu \mathrm{g}, 0.01 \mathrm{mg}, 0.1 \mathrm{mg}$ and 1 $\mathrm{mg} / \mathrm{mL}$ ) were applied. FC and HR were recorded before and after the administration of QSP in the aforementioned doses.

\section{Statistical analysis}

The experimental data of the control and treated animal groups are expressed as their mean \pm SEM. The data of the control group were compared with those of the treated group and variations among different 
treated animal groups were also statistically analyzed using one-way ANOVA (Turkey's multiple comparison test) and the probability value of $<0.05$ was considered as statistically significant.

\section{RESULTS AND DISCUSSION Physical parameters}

The mice were carefully observed on daily basis for 14 days as to their physical parameters after being treated with QSP. It was noticed that all the mice remained healthy after the treatment and no mortality was seen during this study. There were no signs of dermal, ocular and mucosal irritation in any treated animal. All the treated animals showed normal behavior and no changes in their behavioral pattern, such as tremors, sleep, diarrhea and salivation, were apparent. Therefore, QSP is considered safe in doses of up to $5 \mathrm{~g} / \mathrm{kg}$ body weight as no abnormalities were observed during the 14 days' observations.

\section{Estimation of body weight, food and water consumption}

During the observation of body weight, food and water consumed by both control and treated mice, there was a slight decrease in body weight of the mice from day 1 to 3 , while a gradual increase in weight was observed afterwards (Table 1). This decrease in body weight is explained by less consumption of food during the initial days after the treatment. Being a highly swellable material, the presence of QSP in the gastrointestinal tract of the animals may lead to a feeling of stomach fullness, which ultimately reduced food consumption. Similarly, food intake and water consumption were also slightly less, compared to the control, on the first day of the treatment, however, no significant difference of food and water intake and body weight was noticed after day 3 .

Table 1

Body weight, food and water intake of control and treated animals

\begin{tabular}{clcccc}
\hline S/No & $\begin{array}{l}\text { Clinical } \\
\text { observations }\end{array}$ & $\begin{array}{c}\text { Group I } \\
\text { control }\end{array}$ & $\begin{array}{c}\text { Group II } \\
\text { treated }(1 \mathrm{~g} / \mathrm{kg})\end{array}$ & $\begin{array}{c}\text { Group III } \\
\text { treated }(2 \mathrm{~g} / \mathrm{kg})\end{array}$ & $\begin{array}{c}\text { Group IV } \\
\text { treated }(5 \mathrm{~g} / \mathrm{kg})\end{array}$ \\
\hline 1 & Body weight $(\mathrm{g})$ & & & \\
\hline & Pretreatment & $27.8 \pm 0.36$ & $28.8 \pm 1.51$ & $26.7 \pm 0.89$ & $29.6 \pm 0.91$ \\
& Day 1 & $27.8 \pm 0.75$ & $28.6 \pm 1.51$ & $26.0 \pm 0.98$ & $29.4 \pm 0.46$ \\
& Day 2 & $27.9 \pm 0.25$ & $28.3 \pm 1.38$ & $25.8 \pm 1.11$ & $29.1 \pm 1.14$ \\
& Day 3 & $28.1 \pm 0.30$ & $28.1 \pm 1.18$ & $25.7 \pm 1.00$ & $28.3 \pm 1.01$ \\
& Day 7 & $28.9 \pm 0.35$ & $28.2 \pm 1.17$ & $26.6 \pm 0.90$ & $29.1 \pm 0.96$ \\
& Day 14 & $29.3 \pm 0.27$ & $28.8 \pm 1.10$ & $26.8 \pm 0.90$ & $29.9 \pm 0.93$ \\
\hline 2 & Food intake $(\mathrm{g})$ & & & \\
\hline & Pretreatment & $2.9 \pm 0.15$ & $3.1 \pm 0.20$ & $3.0 \pm 0.15$ & $3.1 \pm 0.15$ \\
& Day 1 & $2.8 \pm 0.15$ & $2.4^{*} \pm 0.21$ & $2.4 * \pm 0.15$ & $2.5 * \pm 0.10$ \\
& Day 2 & $2.9 \pm 0.06$ & $2.6 \pm 0.15$ & $2.8 \pm 0.12$ & $2.5 * * \pm 0.06$ \\
& Day 3 & $2.8 \pm 0.06$ & $2.9 \pm 0.10$ & $3.0 * * \pm 0.30$ & $3.1 * * \pm 0.15$ \\
& Day 7 & $3.0 \pm 0.10$ & $3.1 * * \pm 0.20$ & $2.9 * * \pm 0.10$ & $3.1 * * \pm 0.15$ \\
& Day 14 & $3.0 \pm 0.10$ & $3.2^{* *} \pm 0.32$ & $3.1 * * \pm 0.15$ & $3.1 * * \pm 0.10$ \\
\hline Water intake $(\mathrm{mL})$ & & & \\
\hline & Pretreatment & $11.9 \pm 0.86$ & $11.8 \pm 0.85$ & $12.1 \pm 0.61$ & $11.9 \pm 0.40$ \\
& Day 1 & $12.3 \pm 0.86$ & $11.1 \pm 0.36$ & $12.0 \pm 0.40$ & $11.7 \pm 0.40$ \\
& Day 2 & $12.5 \pm 0.53$ & $12.4 \pm 0.91$ & $12.3 \pm 0.40$ & $12.0 \pm 0.36$ \\
Day 3 & $12.5 \pm 0.71$ & $12.7 \pm 0.60$ & $12.4 \pm 0.30$ & $12.1 \pm 0.20$ \\
Day 7 & $12.6 \pm 0.62$ & $12.8 \pm 0.96$ & $12.7 \pm 0.30$ & $12.3 \pm 0.21$ \\
& Day 14 & $12.3 \pm 0.36$ & $12.7 \pm 0.60$ & $12.8 \pm 0.30$ & $12.3 \pm 0.40$ \\
\hline
\end{tabular}

Body weight, food intake and water intake is expressed as mean \pm SEM, $* P<0.05$ as significant difference as compared to control, $* * P<0.05$ as significant difference within the group

\section{Ocular and dermal irritation}

The assessment of ocular and dermal safety of excipients to be used in oral dosage form, as inhalation or dermal preparations is mandatory as per the guidelines of the United States Pharmacopeia. The results of these experiments 
indicated that QSP does not cause ocular and dermal irritation. There were no signs of eye redness, iritis, conjunctivitis and corneal opacity immediately after instillation of the QSP solution into the eye and up to $72 \mathrm{~h}$ of the instillation. The eye color of the control and treated eye was also comparable. According to Kay and Calandra's eye irritation score and Draize's scale, ${ }^{41,42}$ all the treated groups acquired 0.0 score on both scales, which indicates the ocular safety of QSP. Similarly, the skin of the rabbits treated with QSP showed no signs of rashes, redness, swelling and any other abnormalities. The skin of the treated group animals was also similar in appearance to that of the control, which suggested the dermal safety of QSP at a high dose.

\section{Relative organ body weight and histopathology of vital organs}

On day $15^{\text {th }}$, the mice of both control and treated groups were sacrificed and the relative organ body weight of all vital organs, e.g. heart, kidney, liver, spleen, stomach, per $100 \mathrm{~g}$ of total body weight was determined (Table 2). It was concluded that there was no statistically significant difference in relative organ body weight of the control and treated mice. The histopathological studies of vital organs showed no signs of degeneration or lesions in the treated animals, compared with the control group (Figs. 1 and 2). These outcomes clearly establish the oral safety of QSP in animal models.

Table 2

Relative organ body weight of mice

\begin{tabular}{lcccccc}
\hline Groups & Dose & Heart & Liver & Kidney & Spleen & Stomach \\
\hline Control & & $0.50 \pm 0.02$ & $1.96 \pm 0.12$ & $0.82 \pm 0.05$ & $0.68 \pm 0.05$ & $1.14 \pm 0.05$ \\
Group II & $1 \mathrm{~g} / \mathrm{kg}$ & $0.53 \pm 0.02$ & $1.85 \pm 0.08$ & $0.81 \pm 0.04$ & $0.74 \pm 0.03$ & $1.06 \pm 0.08$ \\
Group III & $2 \mathrm{~g} / \mathrm{kg}$ & $0.52 \pm 0.02$ & $1.98 \pm 0.12$ & $0.88 \pm 0.04$ & $0.71 \pm 0.04$ & $1.05 \pm 0.07$ \\
Group IV & $5 \mathrm{~g} / \mathrm{kg}$ & $0.51 \pm 0.02$ & $1.85 \pm 0.11$ & $0.91 \pm 0.03$ & $0.80 \pm 0.03$ & $1.15 \pm 0.07$ \\
\hline
\end{tabular}

Organ weight is expressed as mean relative organ body weight \pm SEM
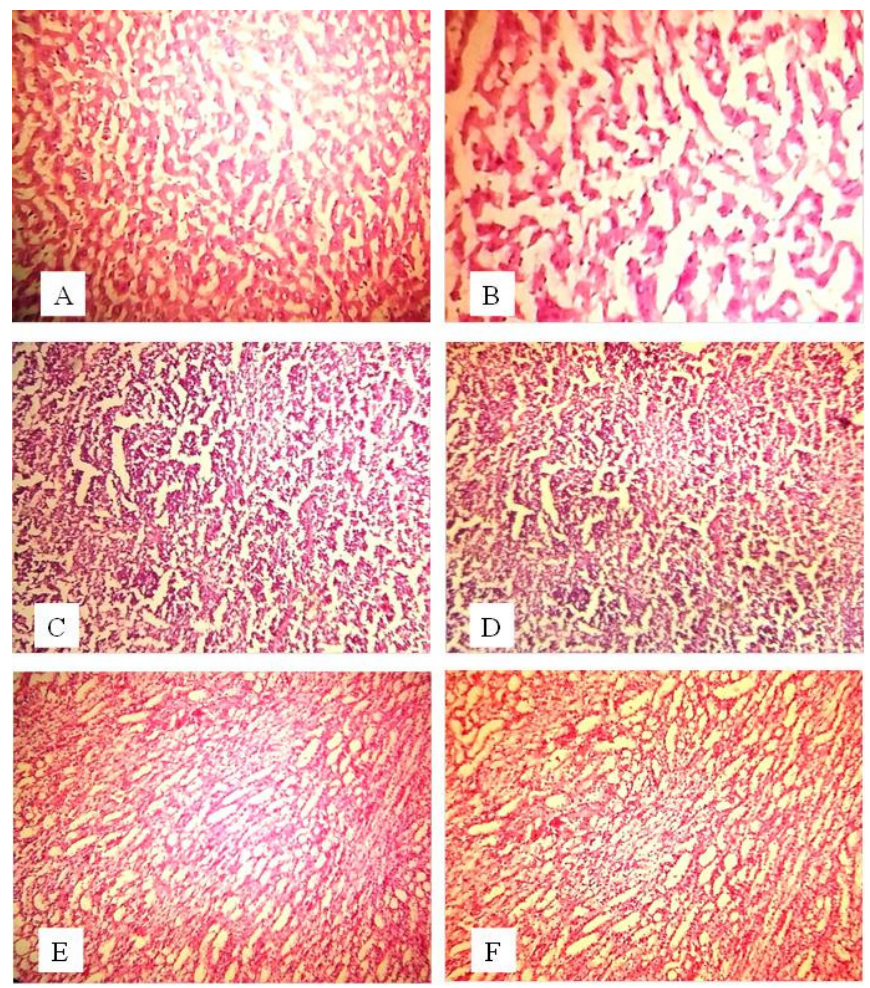

Figure 1: Histopathology of liver (A: treated, B: control), spleen (C: treated, D: control) and intestine (E: treated, F: control) 

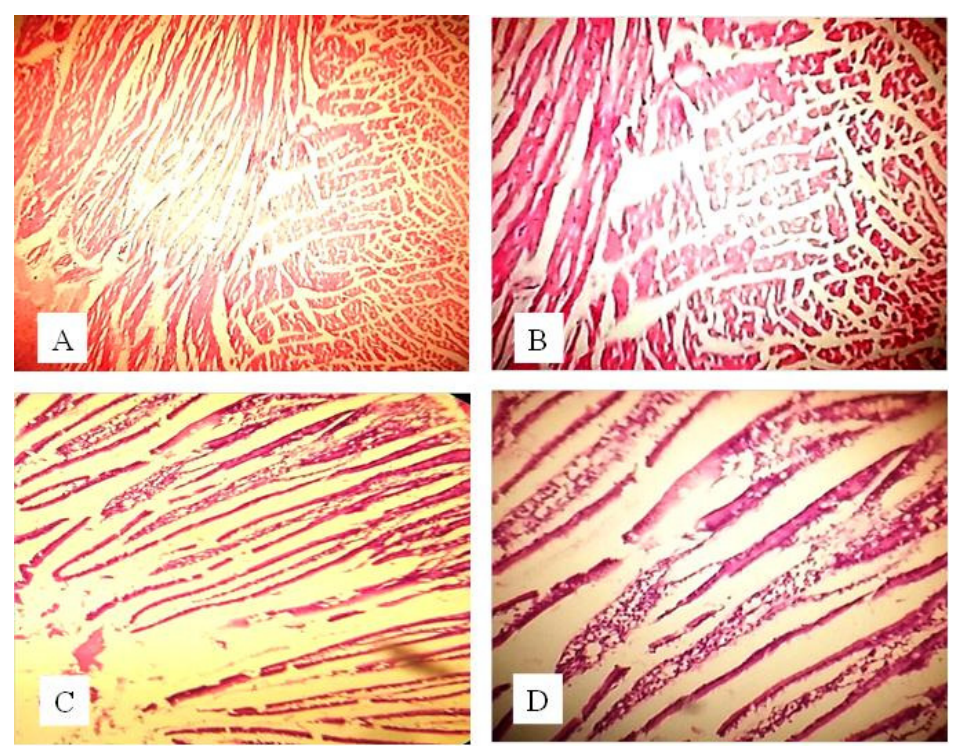

Figure 2: Histopathology of heart (A: treated, B: control) and kidney (C: treated, D: control)

Table 3

Haematology and blood chemistry of mice

\begin{tabular}{lcccc}
\hline Test & $\begin{array}{c}\text { Group I } \\
\text { control }\end{array}$ & $\begin{array}{c}\text { Group II } \\
\text { treated }(1 \mathrm{~g} / \mathrm{kg})\end{array}$ & $\begin{array}{c}\text { Group III } \\
\text { treated }(2 \mathrm{~g} / \mathrm{kg})\end{array}$ & $\begin{array}{c}\text { Group IV } \\
\text { treated }(5 \mathrm{~g} / \mathrm{kg})\end{array}$ \\
\hline Haematology & & & & \\
\hline Total WBCs $\left(\times 10^{3} / \mu \mathrm{L}\right)$ & $8.17 \pm 0.25$ & $8.27 \pm 0.60$ & $8.20 \pm 0.40$ & $8.33 \pm 0.15$ \\
RBCs $\left(\times 10^{6} / \mu \mathrm{L}\right)$ & $8.29 \pm 0.20$ & $8.03 \pm 0.31$ & $7.97 \pm 0.47$ & $8.53 \pm 0.37$ \\
Platelets $\left(\times 10^{3} / \mu \mathrm{L}\right)$ & $548 \pm 3.06$ & $550 \pm 7.02$ & $556 \pm 9.71$ & $565 \pm 4.58$ \\
Hb $(\mathrm{g} / \mathrm{dL})$ & $12.3 \pm 0.15$ & $11.9 \pm 0.31$ & $12.1 \pm 0.60$ & $12.2 \pm 0.36$ \\
\hline Liver profile & & & & \\
\hline ALT $(\mathrm{U} / \mathrm{L})$ & $54 \pm 2.52$ & $57 \pm 3.00$ & $58 \pm 3.51$ & $58 \pm 1.52$ \\
AST $(\mathrm{U} / \mathrm{L})$ & $143 \pm 2.65$ & $143 \pm 3.06$ & $116 \pm 4.04$ & $143 \pm 4.58$ \\
\hline Renal profile & & & \\
\hline Creatinine $(\mathrm{mg} / \mathrm{dL})$ & $0.44 \pm 0.05$ & $0.46 \pm 0.03$ & $0.47 \pm 0.03$ & $0.47 \pm 0.06$ \\
\hline Lipid profile & & & \\
\hline Serum cholesterol & $146 \pm 2.52$ & $147 \pm 3.06$ & $150 \pm 3.05$ & $149 \pm 3.60$ \\
$\quad$ Serum triglycerides & $113 \pm 2.65$ & $112 \pm 2.52$ & $111 \pm 3.60$ & $111 \pm 3.05$ \\
\hline
\end{tabular}

Haematological parameters and blood chemistry is expressed as their mean values \pm SEM

\section{Haematology and biochemical analysis of blood}

Blood chemistry and haematology results of both treated and control group are summarized in Table 3. It is evident that all the haematological parameters, i.e. RBCs, WBCs, platelet counts and $\mathrm{Hb}$, are in normal ranges and there is no significant difference in the haematological picture of the control and treated mice, as well as within the treated animals. Blood chemistry results, i.e., the liver profile, renal profile, serum triglyceride and cholesterol level, were found in normal ranges, indicating no signs of toxicity of QSP in the treated animals.

\section{Safety pharmacology}

The cardiac safety of QSP was evaluated according to the safety procedures for excipients set in the International Conference of Harmonization (ICH guidance, 2005). The effect of QSP on heart rate and the force of contraction of the heart were evaluated on rabbit heart (Figs. 3 and 4). It is evident that there is only a mild increase in the contraction force of the heart 
muscles after application of the solution of QSP

heart rate was noticed. $(1 \mathrm{mg} / \mathrm{mL})$. However, no significant effect on the

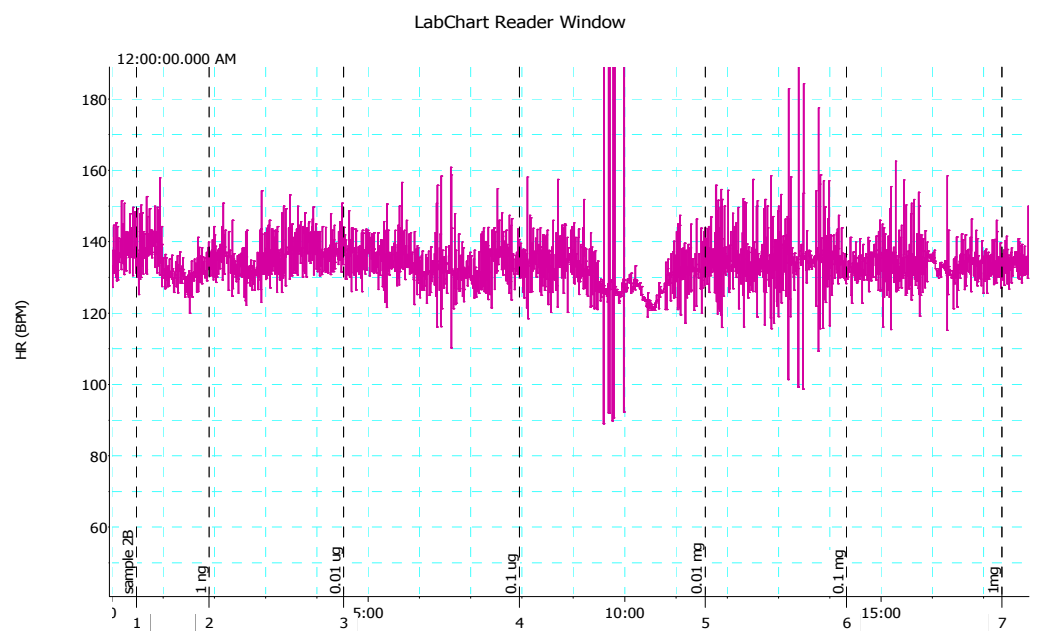

Figure 3: Effect of different concentrations of QSP on heart rate

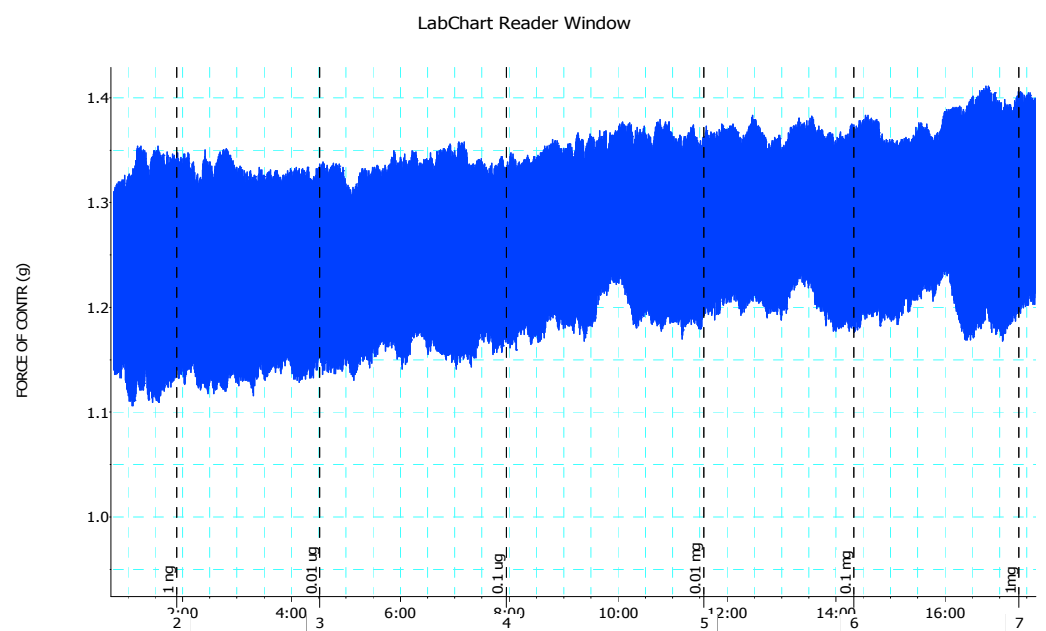

Figure 4: Effect of different concentrations of QSP on heart contraction force

\section{CONCLUSION}

The outcome of different parameters, including physical parameters, such as general health of the treated animals, their behavioral pattern, body weight, food and water consumption, were normal and no abnormalities were noticed in the acute toxicological evaluation of QSP. The evaluation of biochemical parameters, the histopathology of vital organs and the safety pharmacology studies also showed no abnormalities in the treated animals. Furthermore, the instillation of QSP into the eyes and the application onto the skin caused neither iritis nor dermatitis, demonstrating that QSP is safe as an oral drug excipient and it can also be incorporated safely as excipient for skin products. However, in order to calculate its $\mathrm{LD}_{50}$, more detailed toxicology studies are recommended.

\section{REFERENCES}

1 X. Z. Zhang, D. Q. Wu and C. C. Chu, Biomaterials, 25, 3793 (2004), https://doi.org/10.1016/j.biomaterials.2003.10.065 2 N. V. Gupta and H. G. Shivakumar, Curr. Drug Deliv., $\quad$ 6, $505 \quad$ (2009), https://doi.org/10.2174/156720109789941722

C. Maderuelo, A. Zarzuelo and J. M. Lanao, $J$. Control. Release, 154, 2 (2011), https://doi.org/10.1016/j.jconrel.2011.04.002 
4 G. Ponchel and J. M. Irache, Adv. Drug Deliv. Rev., 34, 191 (1998), https://doi.org/10.1016/S0169409X(98)00040-4

5 F. Atyabi, H. L. Sharma, H. A. H. Mohammad and J. T. Fell, J. Control. Release, 42, 25 (1996), https://doi.org/10.1016/0168-3659(96)01343-0

6 M. T. Haseeb, M. A. Hussain, S. H. Yuk, S. Bashir and M. Nauman, Carbohyd. Polym., 136, 750 (2016), https://doi.org/10.1016/j.carbpol.2015.09.092

7 G. Muhammad, M. A. Hussain, M. U. Ashraf, M. T. Haseeb, S. Z. Hussain et al., RSC Adv., 6, 23310 (2016), https://doi.org/10.1039/C5RA23088H

J. Chen, W. E. Blevins, H. Park and K. Park, J. Control. Release, 64, 39 (2000), https://doi.org/10.1016/S0168-3659(99)00139-X

9 K. M. Wood, G. M. Stone and N. A. Peppas, Acta Biomater., $\quad 6, \quad 48 \quad$ (2010), https://doi.org/10.1016/j.actbio.2009.05.032

10 T. Betancourt, J. Pardo, K. Soo and N. A. Peppas, J. Biomed. Mater. Res., 93, 175 (2010), https://doi.org/10.1002/jbm.a.32510

11 M. T. Haseeb, M. A. Hussain, S. Bashir, M. U. Ashraf and N. Ahmad, Drug Dev. Ind. Pharm., 43, 409

(2017),

https://doi.org/10.1080/03639045.2016.1257017

12 M. U. Ashraf, M. A. Hussain, S. Bashir and M. T. Haseeb, J. Drug Dev. Sci. Tech., 45, 455 (2018), https://doi.org/10.1016/j.jddst.2018.04.008

13 W. E. Hennink and C. F. Van Nostrum, Adv. Drug Deliv. Rev., 64, 223 (2012), https://doi.org /10.1016/j.addr.2012.09.009

14 A. Pourjavadi, H. Ghasemzadeh and R. Soleyman, J. Appl. Polym. Sci., 105, 2631 (2007), https://doi.org/10.1002/app.26345

15 W. B. Wang and A. Q. Wang, Carbohyd. Polym., 80, $1028 \quad$ (2010), $\quad$ https://doi.org /10.1016/j.carbpol.2010.01.020

16 Y. C. Marcano and M. A. Sabino G., Cellulose Chem. Technol., 52, $559 \quad$ (2018), http://www.cellulosechemtechnol.ro/pdf/CCT78(2018)/p.559-567.pdf

17 H. S. Kim, J. Yang, K. Kim and U. S. Shin, Mater. Sci. Eng. C, 98, 472 (2019), https://doi.org /10.1016/j.msec.2018.11.051

18 R. Fujioka, Y. Tanaka and T. Yoshimura, J. Appl. Polym. Sci., 114, 612 (2009), https://doi.org /10.1002/app.30600

19 Y. Chen, Y. F. Liu, H. M. Tan and J. X. Jiang, Carbohyd. Polym., 75, $287 \quad$ (2009), https://doi.org/10.1016/j.carbpol.2008.07.022

${ }^{20}$ M. Popa, B. C. Ciobanu, L. Ochiuz, J. Desbrieres, C. S. Stan et al., Cellulose Chem. Technol., 52, 353 (2018),

http://www.cellulosechemtechnol.ro/pdf/CCT56(2018)/p.\%20353-370.pdf

21 X. Chen, M. Fan, H. Tan, B. Ren, G. Yuan et al., Mater. Sci. Eng. C, 101, 619 (2019), https://doi.org/10.1016/j.msec.2019.04.012
22 R. Yegappan, V. Selvaprithiviraj, S. Amirthalingam and R. Jayakumar, Carbohyd. Polym., 198 385

(2018)

https://doi.org/10.1016/j.carbpol.2018.06.086

23 B. S. Patil, V. S. Mastiholimath and A. R. Kulkarni, Orient. Pharm. Exp. Med., 11, 123 (2011), https://doi.org/10.1007/s13596-011-0012-8

24 M. A. Hussain, G. Muhammad, I. Jantan and S. N. A. Bukhari, Polym. Rev., 56, 1 (2015), https://doi.org/10.1080/15583724.2015.1078351

25 M. S. Iqbal, J. Akbar, M. A. Hussain, S. Saghir and M. Sher, Carbohyd. Polym., 83, 1218 (2011). https://doi.org/10.1016/j.carbpol.2010.09.024

26 R. Dimatteo, N. J. Darling and T. Segura, $A d v$. Drug Deliv. Rev., 127, $167 \quad$ (2018), https://doi.org/10.1016/j.addr.2018.03.007

27 M. Amin, M. A. Hussain, S. A. B. Bukhari, M. Sher and Z. Shafiq, Cellulose Chem. Technol., 51, 245 (2017), http://www.cellulosechemtechnol.ro/pdf/CCT34(2017)/p.245-252.pdf

28 A. Erum, S. Bashir, S. Saghir, U. R. Tulain, U. Saleem et al., Drug Chem. Toxicol., 38, 300 (2015), https://doi.org/10.3109/01480545.2014.956219

${ }^{29}$ M. T. Haseeb, S. Bashir, M. A. Hussain, M. U. Ashraf, A. Erum et al., Braz. J. Pharm. Sci., 54, e17459 (2018), http://dx.doi.org/10.1590/s217597902018000217459

30 A. P. Oliveira, J. A. Pereira, P. B. Andrade, P. Valentao, R. M. Seabra et al., J. Agric. Food Chem., 55, 7926 (2007), https://doi.org/10.1021/jf0711237

31 S. Fattouch, P. Caboni, V. Coroneo, C. I. Tuberoso, A. Angioni et al., J. Agric. Food Chem., 55, 963 (2007), https://doi.org/10.1021/jf062614e

32 S. Kultur, J. Ethnopharmacol., 111, 341 (2007), https://doi.org/10.1016/j.jep.2006.11.035

33 Y. Hamauzu, T. Inno, C. Kume, M. Irie and K. Hiramatsu, J. Agric. Food Chem., 54, 765 (2006), https://doi.org/10.1021/jf052236y

34 M. Carvalho, B. M. Silva, R. Silva, P. Valentao, P. B. Andrade et al., , J. Agric. Food Chem., 58, 3366 (2010), https://doi.org/10.1021/jf903836k

35 M. Aslan, N. Orhan, D. D. Orhan and F. Erugan, $J$. Ethnopharmacol., $\quad \mathbf{1 2 8}, \quad 384 \quad$ (2010), https://doi.org/10.1016/j.jep.2010.01.040

36 A. G. Osman, M. Koutb and A. El-D. H. Sayed, J. Photochem. Photobiol. B., 99, 1 (2010), https://doi.org/10.1016/j.jphotobiol.2010.01.002

37 T. Kawahara and T. Lizuka, Cytotechnology, 63, 143

(2011), https://link.springer.com/article/10.1007/s10616-0109323-8

38 M. R. Vignon and C. Gey, Carbohyd. Res., 307, $107 \quad$ (1998), https://doi.org/10.1016/S00086215(98)00002-0

39 OECD (Organization for Economic Co-operation and Development) guideline for testing of chemicals. Acute oral toxicity-fixed dose procedure No. 420 (2001), 
https://ntp.niehs.nih.gov/iccvam/suppdocs/feddocs/oec d/oecd_gl420.pdf

40 M. U. Ashraf, M. A. Hussain, G. Muhammad, M. T. Haseeb, S. Bashir et al., Int. J. Biol. Macromol., 95, 138 https://doi.org/10.1016/j.ijbiomac.2016.11.057

${ }^{41}$ J. H. Kay and J. C. Calandra, J. Soc. Cosmet. Chem., 13, $281 \quad$ (1962), http://journal.scconline.org/contents/cc1962/cc013n06. html

42 J. H. Draize, J. Pharmacol. Exp. Ther., 82, 377 (1944), https://jpet.aspetjournals.org/content/82/3/377

43 G. Sahgal, S. Ramanathan, S. Sasidhara, M. N. Mordi, S. Ismail et al., Pharmacog. Res., 2, 215 (2010), https://doi.org/10.4103/0974-8490.69107

44 ICH Guidance for Industry (2005), S7A, safety pharmacology studies for human pharmaceuticals ICH, https://www.ich.org/fileadmin/Public_Web_Site/ICH_ Products/Guidelines/Safety/S7A/Step4/S7A_Guideline .pdf

N. H. Syed, Q. Mahmood, M. Ahmed and M. S. Akhtar, Bangl. J. Pharmacol., 8, 311 (2013), https://doi.org/10.3329/bjp.v8i3.15080 